\begin{tabular}{l|l|l|l}
\hline & $7_{=}^{\text {th }}$ CONGIC & Blucher Design Proceedings \\
$7^{\text {th }}$ CIDI & $\begin{array}{l}7^{\text {th }} \text { Information Design } \\
\text { International Conference }\end{array}$ & $\begin{array}{l}7^{\text {th }} \text { Information Design } \\
\text { Student Conference }\end{array}$ & $\begin{array}{l}\text { Setembro, 2015 }- \text { num. 2, vol.2 } \\
\text { proceedings.blucher.com.br }\end{array}$
\end{tabular}

\title{
Efeitos do heads-up display no processo de imersão: uma pesquisa com jogadores
}

\author{
Effects of the heads-up display in the occurrence of immersion: an experiment with \\ gamers
}

\author{
Rafael Pereira de Araujo e Virgínia Tiradentes Souto
}

videogames, imersão, heads-up display (HUD)

O design de uma interface gráfica num jogo de videogame pode afetar diretamente a experiência de imersão que o jogador vivencia durante a atividade. Existe uma gama de elementos de design de interface que podem afetar o fenômeno da imersão nos videogames, entre eles o heads-up display (HUD). No contexto de videogames, HUD pode ser definido como um conjunto de elementos gráficos projetados na tela para transmitir informações ao jogador durante a execução do jogo. Este estudo tem como objetivo investigar os efeitos do Heads-Up Display (HUD) no processo de imersão num jogo. Para tanto, uma pesquisa com jogadores foi conduzida. A partir deste experimento foram avaliados os efeitos de diferentes elementos do design de HUD, bem como a percepção dos usuários sobre o fenômeno. Os resultados desta pesquisa apontam para algumas diretrizes sobre o design de HUDs em jogos imersivos.

videogames, immersion, heads-up display (HUD)

The user interface in a videogame can affect the user's experience of immersion during gameplay. Several components of said interface can affect the phenomena differently, one of them being the heads-up display (HUD). In this context, the HUD can be understood as the combination of all visual elements projected onscreen to convey information to the player. This study aims at investigating the effects of the HUD in the occurrence of immersion within a game. To do so, an experiment with gamers was conducted. From this point, different aspects of immersion were evaluated, as well as the influence of specific elements within the HUD and the perception of gamers about each aspect. The study is concluded by proposing some design elements that should be noted when designing a HUD for an immersive videogame.

\section{Introdução}

Jogos de videogame permitem aos jogadores vivenciar diversas experiências durante sua execução, tais como sensações de imersão, desafio, controle e diversão. A imersão, em particular, é considerada uma experiência complexa, com diversas possibilidades dentro do mundo dos jogos de videogame (ERMI e MÄYRÄ, 2005). Por meio de um design de jogo que permita ao jogador vivenciar experiências de imersão, é possível atribuir a um jogo características emocionais, permitir um escapismo do mundo real ou simplesmente um nível de engajamento que torne o jogo mais atraente para o usuário.

R. P. Araújo, V. T. Souto. 2015. Efeitos do heads-up display no processo de imersão: uma pesquisa com jogadores. In: C. G. Spinillo; L. M. Fadel; V. T. Souto; T. B. P. Silva \& R. J. Camara (Eds). Anais [Oral] do 7ํㅡㄹ Congresso Internacional de Design da Informação/Proceedings [Oral] of the 7th Information Design International Conference | CIDI 2015 [Blucher Design Proceedings, num.2, vol.2]. São Paulo: Blucher, 2015. ISSN 2318-6968, DOI 10.5151/designpro-CIDI2015-cidi_49 
Existe uma gama de elementos de design de interface que podem afetar o fenômeno da imersão nos videogames, como por exemplo: menus, sequências interativas, e o heads-up

display. Os "Heads-up displays" (HUD) consistem, de modo geral, em projeções gráficas realizadas numa tela que permitem ao usuário de algum sistema ou produto obter informação sem desviar sua atenção seja ela de uma janela, uma tela de jogo ou algum outro tipo de interface dessa natureza. No contexto de videogames, são exemplos de HUD: mapas, indicadores de saúde do personagem ou posição num desafio competitivo (WILSON, 2006).

O HUD é, portanto, uma peça crucial do design de interface de um jogo, pois oferece ao jogador informações úteis ao jogo, podendo afetar a paisagem visual e a carga cognitiva transmitida ao jogador. A maneira como ele é apresentado impacta na própria qualidade do jogo, uma vez que a exibição gráfica pode ter reflexos em todo o estilo visual do jogo, nos dados apresentados (o que por sua vez influencia até mesmo a narrativa), dentre outros elementos, como comunicação social durante o jogo.

Este estudo tem como objetivo investigar os efeitos do Heads-Up Display (HUD) no processo de imersão num jogo. Para tanto uma pesquisa com jogadores foi conduzida tendo como objetivo principal avaliar os efeitos de diferentes elementos do design de HUD, bem como a percepção dos usuários sobre o fenômeno. Além deste experimento, são apresentados conceitos e características dos HUDs em jogos de videogame, e também uma breve revisão da literatura sobre o assunto.

\section{HUDs em jogos de videogame: características e revisão da literatura}

No contexto de videogames, HUD pode ser definido como um conjunto de elementos gráficos projetados na tela para transmitir informações ao jogador durante a execução do jogo. Observando-se a grande quantidade de dados que um HUD pode proporcionar ao jogador, devem-se considerar quais informações serão transmitidas e como isto será feito. Boa parte das informações em muitos gêneros de jogo cumpre a importante função de compensar o usuário em sua deficiência de perceber o mundo de jogo como alguém inserido no mundo fictício. Num jogo de tiros, por exemplo, o jogador não tem como sentir o peso da arma que ele carrega, tampouco ter ciência de quanta munição está disponível em seu equipamento. Cabe ao jogo dispor informações que facilitem a tomada de decisão como ocorreria no mundo real - caso seja de interesse dos desenvolvedores. Suprimir informações pode ter como efeito o prejuízo na performance de execução do jogo, dificultando a utilização por parte do jogador em um ponto que está externo ao próprio mundo fictício. Esse efeito pode limitar o efeito de suspensão da descrença, dificultando a imersão do usuário naquele jogo.

Por outro lado, existem obstáculos inerentes à exibição gráfica de muita informação na tela, tais como a onisciência e o obstáculo visual. A onisciência consiste na apresentação de uma grande quantidade de informação, em muitos casos acima do que um protagonista de uma história teria. Trata-se de um recurso semelhante à figura do narrador onisciente (SHERLOCK, 2005) que se estende aos jogos especialmente por meio dos HUDs e dos ângulos de câmera panorâmicos. Um exemplo de onisciência pode ser visto em jogos de ação: em um desafio no qual o jogador deve enfrentar um poderoso oponente, um caso de onisciência pode ser a exibição de um gráfico com a saúde desse inimigo. Ao ter acesso ao gráfico, o jogador passa a saber o quanto ele terá que lutar até que o oponente seja derrotado, facilitando muito de sua tomada de decisão. Caso tal informação fosse omitida, as decisões talvez fossem mais ponderadas e deixariam o jogador em dúvida, assustado ou receoso com o combate. A supressão dessas emoções no jogo pode, portanto, acarretar na diminuição do seu poder em envolver o jogador em fortes emoções que teriam vínculo com sua imersão no jogo.

É importante lembrar que o julgamento da interferência visual e da quantidade de informações apresentada varia de acordo com a proposta do jogo, inclusive dentro de um

Anais [Oral] do 7ํㅡㄹ Congresso Internacional de Design da Informação | CIDI 2015

Proceedings [Oral] of the 7th Information Design International Conference / IDIC 2015 
mesmo gênero. Além disso, não se pode desconsiderar a motivação por trás do jogador, responsável por julgar, ainda que indiretamente, o quanto o fenômeno da imersão é afetado.

Moore (2011) afirma que o HUD não deve ser disposto como único elemento de transmissão de informação, sob o risco de se tornar um componente muito demandado em jogos de grande complexidade. Segundo o autor, um bom design de interface passa por um bom balanço entre elementos dispostos no mundo do jogo e as informações necessárias para um HUD. Ainda, de acordo com Moore o feedback das ações e comandos pode ser providenciado também pelo próprio mundo do jogo, por meio de "dicas visuais" em elementos menores (e.g. partes do cenário ou detalhes no personagem). Desse modo, alivia-se a carga de informação no HUD e torna desnecessários elementos como mostradores de saúde ou setas apontando objetivos na fase. Uma consequência dessa abordagem é a existência de uma experiência de jogo mais fluida, em que o jogador recebe diretamente no mundo do jogo as informações que necessita, em vez de ter de recorrer à informação textual ou de símbolos dispostos em outras partes da tela.

Foi verificado que boa parte dos estudos sobre o fenômeno da imersão em jogos foca nos fenômenos e elementos de jogo que a afetam, tais como os tipos de imersão (BROWN e CAIRNS, 2004; ERMI e MÄYRÄ, 2005), o efeito de tamanhos de tela (HOU et al. 2012), a progressão de dificuldade do jogo (QIN et al. 2010) e os fatores de personalização e identificação (SEVERO, 2011; PRZYBYLSKI et al. 2011).

Um exemplo de estudo voltado aos elementos de interface gráfica de jogos foi desenvolvido por Fagerholt e Lorentzon (2009). Eles identificaram quais elementos devem ser considerados no desenvolvimento de uma interface gráfica visando a melhor experiência de jogo. Os autores apontaram diretrizes para a aplicação de elementos diegéticos (i.e. elementos dentro do mundo do jogo), meta-representações (i.e. elementos do mundo do jogo representados de maneira diferente, como numa sobreposição, para o jogador) e significantes (i.e. elementos diegéticos que carregam um significado adicional ao que eles representam).

Verificou-se que há poucos estudos que relacionam o HUD com esse processo de imersão. Desta forma, o estudo apresentado abaixo objetiva contribuir com design de interfaces para jogos, área esta ainda carente de investigações.

\section{Experimento com jogadores: método}

Como forma de avaliar os efeitos desses diferentes elementos de desenho de HUD, bem como a percepção dos usuários sobre o fenômeno, optou-se por realizar uma pesquisa com jogadores. A metodologia consistiu em colocar um grupo de usuários em contato com jogos conhecidos, de diferentes gêneros e tipos de HUD. Em seguida, foi ofertado um questionário com perguntas fechadas e abertas sobre a percepção do usuário de cada jogo. Por fim, foram realizados grupos de foco em que perguntas foram incitadas pelo mediador para permitir as discussões. Todo o material foi registrado em áudio e nos questionários.

O experimento foi submetido a uma avaliação por um comitê de ética por meio da Plataforma Brasil. Foram utilizados dois computadores desktop e um console Sony Playstation 3 durante o experimento e o mesmo ocorreu em laboratório.

Foram convidados 10 usuários de diferentes hábitos de uso de videogame, dos gêneros masculino e feminino com idades entre 19 e 30 anos, de profissões variadas e com preferências por diferentes consoles de jogo.

Os jogos utilizados no experimento foram selecionados por critérios como popularidade, boa nota de análises na mídia, diversidade de gêneros e aplicações de HUD e disponibilidade para o teste. São eles Journey (Playstation 3), Battlefield 3 (PC) e The Elder Scrolls V: Skyrim (PC). Outras combinações de jogos seriam possíveis, especialmente analisando-se um mesmo

Anais [Oral] do $7^{\circ}$ Congresso Internacional de Design da Informação | CIDI 2015

Proceedings [Oral] of the 7th Information Design International Conference / IDIC 2015 
gênero, mas nesse caso focou-se em ter um amplo espectro de tipos de jogo também para se adequar ao limitado número de participantes.

Cada jogo foi apresentado em condições de uso adequadas. Todos os usuários assinaram termos de consentimento, apresentaram familiaridade com videogames e foram familiarizados com as condições do teste durante todas as suas etapas. A Figura 1 retrata o experimento durante sua execução com o segundo grupo testado.

Figura 1: Usuários durante o experimento.

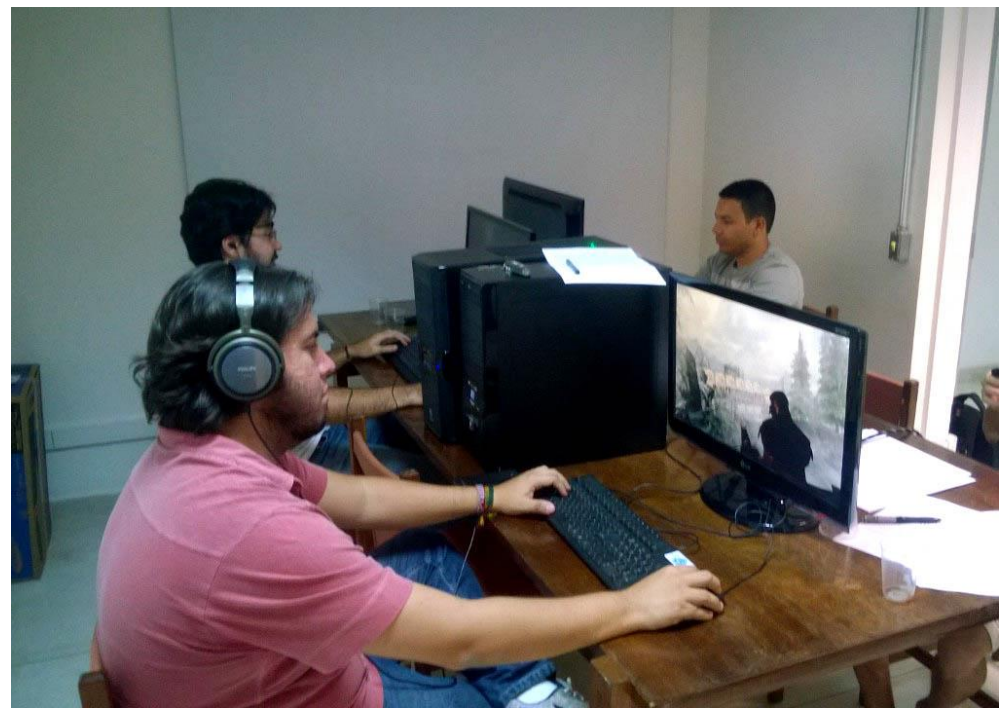

\section{Resultados e discussão}

Após a realização da atividade de jogo, foram conduzidos dois questionários (binário e com afirmações pré-definidas), além do grupo de foco. Os resultados e a discussão dos mesmos foram divididos nestes três instrumentos de teste.

\section{Questionário binário}

O primeiro levantamento realizado se deu por meio da realização do "questionário pós-teste", um conjunto de perguntas sobre HUDs e imersão direcionados ao jogador logo após a execução do jogo. Esse questionário foi respondido de maneira individual por cada usuário e teve por propósito obter respostas diretas pouco tempo após a execução dos jogos apresentados no teste. Esse questionário teve suas respostas divididas em três grupos separados. No primeiro, as perguntas procuraram respostas para questionamentos referentes ao funcionamento do HUD na operação de jogo. As perguntas 1 e 2 tem caráter descritivo (apenas para alinhar o pensamento do usuário) e foram as seguintes:

1. "Durante o jogo, como você obteve informação do progresso da ação e situação de seu personagem?"

2. "Que tipo de informação é essa, no caso desse jogo?"

Já as perguntas de 3 a 7 possuem respostas binárias (sim ou não), com espaço para resposta que permitiu respostas maiores quando de interesse do pesquisado. Essas considerações foram dispostas após a Tabela 1, que compara os resultados dos 3 jogos para as seguintes perguntas de 3 a 7 . 
Tabela 1: Respostas do questionário aberto.

\begin{tabular}{|c|c|c|c|c|c|c|}
\hline & \multicolumn{2}{|c|}{ Journey } & \multicolumn{2}{|c|}{ Skyrim } & \multicolumn{2}{|c|}{ Battlefield 3} \\
\hline & Sim & Não & Sim & Não & Sim & Não \\
\hline $\begin{array}{c}\text { 3. "As informações projetadas na tela são } \\
\text { importantes para que você atinja os objetivos do } \\
\text { jogo?" }\end{array}$ & 8 & 1 & 7 & 1 & 6 & 1 \\
\hline $\begin{array}{l}\text { 4. "Quando você consulta as informações em tela, } \\
\text { você para a ação ou você foca tanto na ação } \\
\text { quanto nas exibições gráficas de dados?" }\end{array}$ & 3 & 2 & 3 & 5 & 5 & 3 \\
\hline $\begin{array}{l}\text { 5. "Você acredita que a consulta a essas } \\
\text { informações pode distrair você dos objetivos?" }\end{array}$ & 1 & 9 & 3 & 6 & 3 & 4 \\
\hline $\begin{array}{l}\text { 6. "Você acha o visual do HUD destoante do visual } \\
\text { do jogo?" }\end{array}$ & 0 & 9 & 3 & 6 & 1 & 8 \\
\hline 7. "O HUD obstrui sua visão do jogo?" & 0 & 9 & 3 & 4 & 1 & 7 \\
\hline
\end{tabular}

A partir da Tabela 1, é possível extrair alguns entendimentos de caráter comparativo entre os jogos, em especial no que tange ao nível de "intrusão" do HUD na experiência de jogo e no processo de imersão. Além disso, conforme mencionado foram consideradas também as justificativas dos entrevistados sobre cada jogo.

No caso de Journey, os usuários apontaram de maneira enfática o HUD minimalista do jogo. Um dos entrevistados criticou essa proposta minimalista, alegando que os comandos básicos foram pouco apresentados, dando a ele a sensação de não estar em pleno controle do personagem.

Maior parte dos entrevistados, por outro lado, ressaltou e elogiou o fato de que o jogo dispõe maior parte das instruções e narrativas por meio de "dicas" visuais nos cenários, como elementos dispostos em locais de destaque ou sequências animadas com o protagonista do jogo. Isso se refere claramente às definições de HUD diegético e não diegético (BABU, 2012). Por fim, verifica-se que o HUD foi considerado pouco intrusivo, e que ele se integra visualmente ao jogo de maneira positiva, de acordo com os entrevistados.

"The Elder Scrolls V: Skyrim" teve mais respostas positivas no que tange à relevância das informações dispostas no HUD. Por outro lado, e conforme apontado pelos entrevistados, o HUD muitas vezes se sobrepõe de maneira indesejável à ação: em boa parte dos casos, ela é interrompida (e a tela esmaecida) para que alguma informação importante seja transmitida ao jogador. Um dos entrevistados apontou ainda que essas pausas afetam seu processo de imersão, quebrando o ritmo do jogo e distraindo-o de seus objetivos. Vale citar que em Skyrim o HUD apresenta de maneira constante uma "bússola" que indica os pontos cardeais e direções relacionadas com objetivos do personagem. Um dos entrevistados apontou que tal indicação constante foi intrusiva no jogo, em especial ao apontar um seta para personagens com quem o jogador deveria interagir.

Anais [Oral] do 7º Congresso Internacional de Design da Informação | CIDI 2015

Proceedings [Oral] of the 7th Information Design International Conference / IDIC 2015 
Já em Battlefield 3 o HUD foi entendido como pouco invasivo e bem integrado visualmente. Ele foi elogiado pela disposição na tela, mas alguns entrevistados comentaram que a quantidade de informação, eventualmente excessiva, pode distrair o jogador. Em outros casos, informações de comando (ordenando o jogador a seguir um personagem ou apertar um botão de ação) foram consideradas muito intrusivas. Em análise ao Quadro 5, nota-se que Battlefield 3, comparado a Skyrim, teve apontado que seu HUD é melhor integrado visualmente. Comparado com o minimalista Journey, ele ficou em desvantagem.

Analisando-se os três jogos em conjunto, é possível perceber peculiaridades relacionadas aos gêneros de jogo. Skyrim é um RPG de mundo aberto, com um grande número de objetivos e estilos de jogo possíveis, o que requer que o usuário manipule uma grande quantidade de informação. Seu HUD busca reduzir a quantidade de informação na tela (o que permite uma apresentação mais clara do mundo fantástico que ele cria), mas por outro lado carrega uma grande quantidade de dados em menus à parte, o que causa interrupções no jogo. Esse tipo de interrupção é um pouco menos prejudicial do que se aplicado num jogo como Battlefield 3. O FPS possui grande foco na ação em um curto espaço de tempo, o que seria muito prejudicado por interrupções como as de Skyrim. No outro extremo tem-se Journey, que possui um ritmo muito mais sereno, bucólico, e não requer uma grande quantidade de informação sendo transmitida em um curto espaço de tempo.

Ainda no caso do Battlefield 3, é notável que algumas inserções do HUD são de comandos pontuais, "emergenciais" que surgem no meio da tela. Alguns entrevistados criticaram e é notável que tais inserções obstruem a visão da ação do jogo. Em uma das cenas do jogo presenciadas por todos os entrevistados durante a etapa de teste, o jogador deve apertar a tecla "barra de espaço" numa cena de ação. O problema apontado e observável no HUD, nesse momento, é que o comando da barra de espaço surge no meio da tela, sendo o único comando passível de ser executado no momento, e obstruindo a visão da ação.

\section{Questionário com afirmações pré-definidas}

Após as perguntas de resposta binária, os entrevistados tiveram como sequência no questionário uma série de itens cuja resposta deveria ser dada numa escala de 1 a 5 . O propósito dessa parte era obter a avaliação dos usuários baseado em afirmações pré-definidas, com o propósito de validar alguns entendimentos em contraste com as respostas abertas do momento anterior do questionário. Cada item era uma afirmação e a escala numérica representava o quanto 0 entrevistado concordava com ela (sendo 1 "concordo totalmente", e 5 "discordo totalmente"). Esses itens versaram sobre afirmações envolvendo o HUD e são apresentados na Tabela 2.

O conjunto das respostas obtidas nesse ponto da avaliação permitiu verificar quais dessas afirmações foram aceitas pela maioria dos entrevistados para cada jogo. Esse dado, em cruzamento com o entendimento das questões anteriores, permite um melhor entendimento dos efeitos desses diferentes HUDs nesses jogos de diferentes gêneros. O Quadro 2 elenca os jogos avaliados, as frases e apresenta marcação das frases que tiveram, em sua maior parte, mais aceitação (sim) ou discordância (não) (i.e. para concordância, maioria de respostas 1 e 2; para discordância, 4 e 5; respostas 3 foram consideradas neutras).

Tabela 2: Questões de escala 1 a 5 - itens de maior concordância

\begin{tabular}{c|c|c|c|c|c|c}
\hline & \multicolumn{2}{|c|}{ Journey } & \multicolumn{2}{c|}{ Skyrim } & \multicolumn{2}{c}{ Battlefield 3 } \\
\hline & Sim & Não & Sim & Não & Sim & Não \\
\hline 1. "As informações do jogo são um recurso do & $X$ & & $X$ & & $X$ & \\
\hline
\end{tabular}

Anais [Oral] do $7^{\circ}$ Congresso Internacional de Design da Informação | CIDI 2015

Proceedings [Oral] of the 7th Information Design International Conference / IDIC 2015 


\begin{tabular}{|c|c|c|c|c|c|}
\hline videogame que me auxiliam a jogar." & & & & & \\
\hline $\begin{array}{l}\text { 2. "As exibições de informação estão entre meu } \\
\text { mundo e o mundo do jogo." }\end{array}$ & & & $\mathrm{x}$ & & \\
\hline $\begin{array}{l}\text { 3. "Essas informações compensam as limitações do } \\
\text { videogame em relação ao mundo do jogo." }\end{array}$ & & & $\mathrm{x}$ & $\mathrm{x}$ & \\
\hline $\begin{array}{l}\text { 4. "As informações que recebo são externas ao } \\
\text { mundo do jogo." }\end{array}$ & & & & & $\mathrm{x}$ \\
\hline 5. "Quando eu jogo este jogo, eu sou o protagonista." & $\mathrm{x}$ & & $x$ & $x$ & \\
\hline $\begin{array}{l}\text { 6. "Eu deixo de ser o personagem e passo a ser o } \\
\text { jogador quando paro para ler as exibições em tela." }\end{array}$ & & $\mathrm{x}$ & & & \\
\hline $\begin{array}{l}\text { 7. "Se eu fosse o próprio personagem, eu saberia } \\
\text { essas informações de outro modo." }\end{array}$ & & & $\mathrm{x}$ & & \\
\hline $\begin{array}{l}\text { 8. "Se não houvesse uma exibição gráfica, eu estaria } \\
\text { em desvantagem dentro do jogo." }\end{array}$ & & $\mathrm{x}$ & $\mathrm{x}$ & $\mathrm{x}$ & \\
\hline 9 "O HUD é parte da paisagem visual do jogo". & $\mathrm{x}$ & & & & \\
\hline
\end{tabular}

Em todos os três jogos, a transmissão de informação para o jogador foi considerada importante para alcançar os objetivos. Todos os jogos passaram ao jogador a sensação de que eles são o protagonista da história, podendo então ser considerados jogos imersivos.

O oitavo item se mostra interessante ao apontar que a ausência do HUD afetaria o desempenho do jogador. Enquanto em Skyrim e Battlefield 3 o HUD é notavelmente relevante para o desempenho do jogador, em Journey as informações dispostas em tela tem por intuito apenas ensinar os movimentos básicos do jogo, bem como alertar sobre informações como salvamento do jogo. Desse modo, houve maior discordância no caso desse jogo. Por outro lado, como o HUD é pouco utilizado em Journey (sendo relevante apenas para comandos iniciais e salvamento), os usuários afirmaram que eles deixam de ser o protagonista e passam a ser o jogador quando consultam essas informações, havendo assim uma quebra do processo de imersão no jogo. Journey foi o único que teve como resposta de concordância que o HUD é parte da paisagem visual do jogo, por outro lado.

\section{Grupo de foco}

O terceiro item da pesquisa, por sua vez, foi o grupo de foco realizado com os usuários. A objetivo dessa parte da pesquisa foi obter informações ligando as linhas de pensamento dos entrevistados e deixando-os mais livres para tecer suas considerações ou ouvir os demais.

O grupo consistiu na reunião dos dois grupos de usuários presentes nas duas datas, sendo 5 pessoas no primeiro dia e 4 no segundo (o sexto entrevistado do primeiro dia ausentouse antes da realização do grupo de foco). Cada grupo foi apresentado às seguintes provocações questionadoras, de modo a iniciar uma discussão em grupo: 
1. "A ideia de um HUD é apresentar informação para o jogador. Como você comparam esse tipo de informação com outros meios? Por exemplo: falas no meio do jogo ou telas de interrupção (como as do cinema mudo)".

2. "Vocês jogaram jogos que apresentam mais e menos informações no HUD. No Skyrim, por exemplo, a informação é mais eventual (que em Battlefield 3). Durante o jogo em si, qual a percepção que vocês tem do ponto de vista visual?"

3. "Como vocês passariam essas informações para o jogador? Podem "viajar" em termos de tecnologia ou conceitos, mesmo que eles não sejam possíveis hoje em dia. Por exemplo, o aparato utilizado pelo desenvolvedor de Gran Turismo que inclina e rotaciona a poltrona de jogo de acordo com a força $\mathrm{G}$ recebida no carro durante a corrida."

Em ambos os casos, os jogadores se envolveram na discussão durante períodos próximos a 30 minutos, em que elaboraram afirmações e questionamentos sobre HUDs, suas aplicações e em especial à ideia de transmissão de informação durante a execução do jogo. As duas sessões foram registradas em áudio e tem abaixo apresentadas algumas transcrições de pontos interessantes apontados pelos usuários.

"Quando a ação é interrompida [para exibir alguma informação] é completamente decepcionante." (Participante da pesquisa)

[Sobre a ideia de por no cenário dicas visuais dos controles e caminhos para o jogador em Journey, em vez de dispor elementos no HUD]"Eu acho até interessante assim porque, principalmente no Journey, acho muito bom que tem nada explicando nada, só ocasionalmente ele te fala alguma coisa que não é tão óbvia...é muito bom quando ele te ensina a jogar o jogo no jogo." (Participante da pesquisa)

[Ainda sobre o tema] "Ele vai interpretar aquilo como sendo uma informação direcionada a ele e não ao personagem nem nada assim, e ao mesmo tempo isso não chega a causar um estranhamento ou quebra de mundo." (Participante da pesquisa)

[Sobre o HUD] "...às vezes não te tira tanto mas por um segundo ali você para, então ela pode te tirar um pouco da imersão e tudo, só que traz uma coisa que é importante, também, você ver o tanto de bala que tem, e você trocar a sua magia, ver o seu life, e tudo são informações que são relevantes mas que naquele momento que você bate o olho ali ela pode te tirar daquele flow, daquele fluxo do jogo."

(Participante da pesquisa)

[Em Skyrim] "Eu detesto quando tem alguma coisa em cima de alguém, aquilo ali pra mim tira totalmente o... né? Olhar e ter em cima do cara [uma seta]. Pra mim não tem problema de ter... principalmente no Battlefield, aquela coisa que espelha meio de lado, ficou muito bacana. Ou então no próprio Skyrim, que a barra de vida é bastante discreta, mas você ter uma bússola em cima da sua cabeça, eu acho desnecessário sempre. Acho que tira toda... ninguém anda com... um "onde é o norte?" "onde é o norte?"... Acho que é muita informação que você não vai usar."

"É bom [ter informações projetadas na tela] só quando as informações são relevantes, quando você está acostumado a utilizá-las." (Participante da pesquisa)

"O HUD tem que ser funcional, tem que te dar informações ali que você precisa ter naquele momento, naquela hora. Se você precisa de mais informações, o HUD tem que ser maior. Se você precisa de menos, você não vai colocar coisas desnecessárias, coisas que você pode acessar por um menu, por ser mais eventual." (Participante da pesquisa)

É notável que há diferentes perfis de jogador e que isso permite uma influência direta no processo de imersão. Percebe-se que muitos consoles diferentes foram citados pelos jogadores. Isso refletiu também nas preferências de jogos e nas opiniões desses jogadores sobre o processo imersivo em cada um deles. Os entrevistados mais familiarizados com videogames antigos, por exemplo, se mostraram menos interessados na experiência de gameplay de Battlefield 3, que se utiliza de alguns recursos não utilizados em videogames antigos como quick-time events e cenas de diálogo longas no meio da ação.

Por outro lado, alguns entrevistados com maior interesse no desenvolvimento de jogos atentaram para pontos muito específicos no processo de imersão, criticando ou elogiando

Anais [Oral] do 7ํㅡㄹ Congresso Internacional de Design da Informação | CIDI 2015

Proceedings [Oral] of the 7th Information Design International Conference / IDIC 2015 
decisões de design individuais. Um exemplo, citado por mais de um deles, foi o HUD de The Elder Scrolls V: Skyrim, que eventualmente projeta uma seta em cima de personagens importantes da história, como que para guiar o jogador a seguir aquele personagem pelo cenário. O caráter intrusivo desse elemento gráfico foi criticado.

Essa diferença de perfis de jogador no processo de imersão já foi estudada (ÖRTQVIST e LILJEDAHL, 2010), e considerou fatores como a idade do jogador, sua experiência com jogos e seu entendimento da natureza de funcionamento das regras de jogo. No estudo, é verificado que principalmente a idade e a experiência com jogos são fatores de influência verificada na percepção do processo de imersão. É concluído que jogadores mais velhos e jogadores com menos experiência em jogos são mais suscetíveis a vivenciar a imersão.

Comparando-se esse conhecimento com as respostas obtidas na pesquisa, é possível depreender que jogadores mais experientes podem estar atentos em demasia a fatores que game design e a seu desempenho no jogo, o que pode distanciá-los de uma vivência plena, sem interrupções, como seria uma atividade de jogo em estado de "flow" (CSIKSZENTMIHALYI, 1990). Por outro lado, é relevante citar que o grupo mais experiente pode também ser familiarizado com a experiência de imersão, sendo os pontos apontados por Örtqvist e Liljedahl (2010) mais vistos como inclinações ao processo de imersão, e não uma resposta binária "sim/não" para a ocorrência do fenômeno.

Essas considerações foram relevantes ao apontar itens individuais que, no conjunto, podem permitir um melhor aproveitamento das experiências de imersão em jogos. Por outro lado, ficou evidente que há mais de uma visão para um assunto, e que mesmo num grupo de foco com uma quantidade limitada de usuários é notável que há diferentes perfis de jogador.

\section{Conclusões e considerações finais}

Os resultados obtidos nesta pesquisa com jogadores estão alinhados com diversas premissas expostas na bibliografia corrente no que tange ao processo de imersão em videogames. Foi notada, por exemplo, a valorização da utilização de elementos diegéticos na interface, bem como a percepção dos jogadores de que um design pouco apropriado pode afetar o ritmo de jogo, interrompendo a entrega ao fenômeno da imersão por parte dos jogadores.

Os resultados deste pesquisa apontam para algumas conclusões que podem ser utilizadas no desenvolvimento de HUDs para jogos. Entre outros aspectos, a partir dos resultados desta pesquisa conclui-se que:

- Adotar elementos diegéticos para a transmissão de informação podem eliminar a carga cognitiva do HUD;

- Reduzir a quantidade de informações que não sejam relevantes no momento pontual do jogo auxilia a imersão dos jogadores. Isso é, deve ser mostrada somente a informação necessária para aquele momento do jogo;

- A escolha do local do HUD é também um dos aspectos fundamentais do design. $O$ designer deve buscar uma disposição gráfica que interfira o mínimo possível na paisagem visual do jogo.

Estas conclusões podem ser utilizadas como diretrizes no desenvolvimento de HUDs para jogos imersivos, assim como em outros tipos de HUDs que tenham como característica não interferir negativamente no fluxo do jogo.

Como passos adicionais para essa pesquisa, é possível apontar que testes realizados com maior disponibilidade de usuários e ferramentas seriam apropriados. Medições biométricas, por exemplo, dariam uma maior dimensão da atenção que o jogador dispensa na consulta ao HUD, em especial do tempo dedicado à ação e o tipo de distração sensorial que isso causa

Anais [Oral] do 7º Congresso Internacional de Design da Informação | CIDI 2015

Proceedings [Oral] of the 7th Information Design International Conference / IDIC 2015 
(como distrações de percepção ou de tempo gasto com o processamento de informações sobre o jogo em si).

Por fim, este material tem por intuito ampliar a discussão sobre os elementos que compõem um jogo de videogame, não se baseando apenas no valor de um jogo (e suas repercussões socioculturais) como também no cerne de seu desenvolvimento (i.e. elementos gráficos e mecânicas). Importante ressaltar que um melhor entendimento desses elementos também pode ter reflexos em outras disciplinas, como o design de interfaces e demais trabalhos em mídias digitais.

\section{Referências}

BABU, J. Video Game HUDs: Information Presentation and Spatial Immersion. Mestrado. Rochester Institute of Technology. Disponível em: <https://ritdml.rit.edu/handle/1850/15948>.31/10/2014.

CSIKSZENTMIHALYI, M. Flow: The Psychology of Optimal Experience. New York, Harper and Row. 1990.

ERMI, L.; MÄYRÄ, F. Fundamental Components of Gameplay Experience: Analysing Immersion. In: Changing Views: World in Play. Selected Papers of the 2005 Digital Games Research Association's Second International Conferece. Digital Games Research Association DiGRA. 2005. SHERLOCK, K. Narrative Viewpoint. Disponível em: <http://www.grossmont.net/karl.sherlock/English126/Resources/NarrativePOV.pdf>. $02 / 11 / 2014$.

HOU, J. et al. Effects of screen size, viewing angle, and players' immersion tendencies on game experience. Computers in Human Behavior 28 (2012). Elsevier. 2012.

MCGONIGAL, J. A realidade em jogo. Rio de Janeiro, Best Seller. 2012.

MOORE, Alex. 2011. Opinion: UI is the Game, The Game is Ul. Disponível em: < http://www.gamasutra.com/view/news/126450/Opinion_UI_Is_ The_Game_The_Game_Is_Ul.php>. 25/04/ 2014.

ÖRTQVIST, D.; LILJEDAHL, M. Immersion and Gameplay Experience: A Contingency Framework. International Journal of Computer Games Technology (2010). Hindawi. 2010.

PRZYBYLSKI, A. et al. The Ideal Self at Play: The Appeal of Video Games That Let You Be All You Can Be. Psychological Science 23(1) 69-76. APS. 2011.

QIN, $\mathrm{H}$ et al. Effects of different scenarios of game difficulty on player immersion. Interaction with Computers 22, 230-239. Elsevier. 2010.

SEVERO, A. P. N. A estética da personalização do avatar nos processos imersivos em jogos eletrônicos. Mestrado. PUC-SP. 2011.

SHEDROFF, N. 1999. Information interaction design: a unified field theory of design. Disponível em: www.nathan.com/thoughts/unified - cesso 5/2/2010.

SILVA, A. D. 2013. Acessibilidade para daltônicos em textos de páginas web utilizando uma ferramenta para conversão de CSS. In: ConSerpro, Regional SP, dezembro. Disponível em: www.anaisdoconserpro.serpro.gov.br/modules/cadastro de trabalhos/trabalho.php?cod=230 $\underline{\text { \&ano }=2013}$ - acesso 2/2015.

\section{Sobre os autores}

Anais [Oral] do 7º Congresso Internacional de Design da Informação | CIDI 2015

Proceedings [Oral] of the 7th Information Design International Conference / IDIC 2015 
Rafael Pereira de Araujo, Me., UnB, Brasil <rafael.pereira.87@hotmail.com>

Virginia Tiradentes Souto, PhD, UnB, Brasil <v.tiradentes@gmail.com> 